[HANAYRÁ NEGREIROS]

Mestra em Ciência da Religião.

Pesquisadora em indumentária afro-brasileira.

E-mail: hanayra@outlook.com

\title{
Ela pinta como se estivesse bordando': pinturas e vestimentas na obra de Maria Auxiliadora
}

She paints as though she was

embroidering: paintings and garments

in Maria Auxiliadora's work

Maria Auxiliadora: vida cotidiana, pintura e resistência

Curadoria: Adriano Pedrosa e Fernando Oliva Local e período: Museu de Arte de São Paulo Assis Chateaubriand (Masp), São Paulo.

De 10 de março a 2 de junho de 2018. 
"O pessoal é político".

É através dessa breve, porém assertiva frase, que começamos a ler o texto curatorial que nos introduz à vida, às cores e às texturas de Maria Auxiliadora - mulher negra, mineira, artista plástica ${ }^{2}$ e detentora de muitas histórias e memórias.

Ao chegarmos ao piso inferior do Museu de Arte de São Paulo, deparamo-nos com o cinza da parede, que é sobriamente escrita com letras pretas, e acima delas enormes letras escritas em cor de rosa, que lembra o magenta, com o nome da pintora (figura 1). Notamos que toda a exposição foi montada e disposta em paredes igualmente cinzas, assim como a que abriga o texto curatorial inicial - o que nos remete a uma tentativa de destacar ainda mais as muitas cores e diversas texturas das obras de Auxiliadora.

Figura 1: Vista da exposição Maria Auxiliadora: vida cotidiana, pintura e resistência

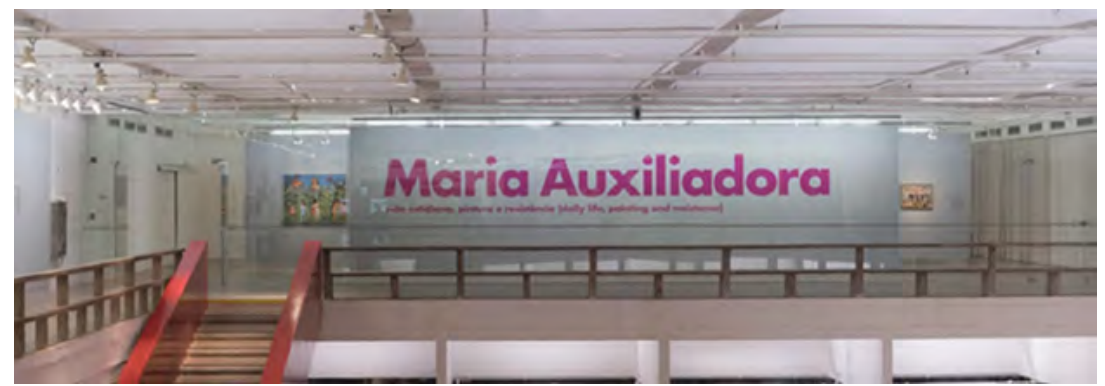

Fonte: ORTEGA, E. Vista da exposição Maria Auxiliadora: vida cotidiana, pintura e resistência. 2018. 1 fotografia.

Figura 2: Vista da exposição Maria Auxiliadora: vida cotidiana, pintura e resistência

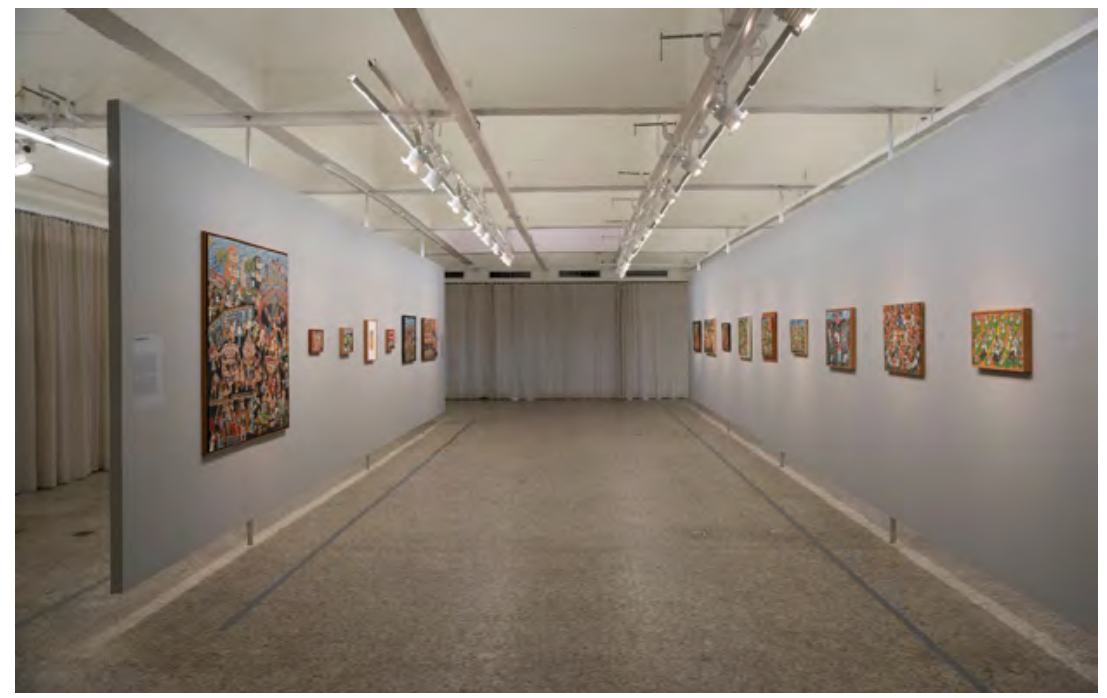

Fonte: ORTEGA, E. Vista da exposição Maria Auxiliadora: vida cotidiana, pintura e resistência. 2018. 1 fotografia. 
Ao longo da mostra, imergimos em uma atmosfera que mistura as memórias da artista, através de fotos e retratos de família, e reportagens datadas principalmente de por volta dos anos 70 , contendo impressões tanto de suas obras como também de sua projeção nacional. Ao analisarmos parte desse material criado a partir da obra da artista, notamos que é recorrente o termo naïf, atualmente tido como ultrapassado por muitos dos artistas, curadores e pesquisadores que caminham em direção às leituras decoloniais sobre as variadas formas de artes, que andam na contramão da "tradicional" arte euro centrada.

Acredita-se que o termo naïf tenha sido atribuído à obra de Auxiliadora justamente por se tratar de uma arte produzida por uma mulher negra e periférica, que havia sido empregada doméstica - ofício comum destinado a muitas mulheres negras como Auxiliadora.

\section{Figura 3: Maria Auxiliadora}

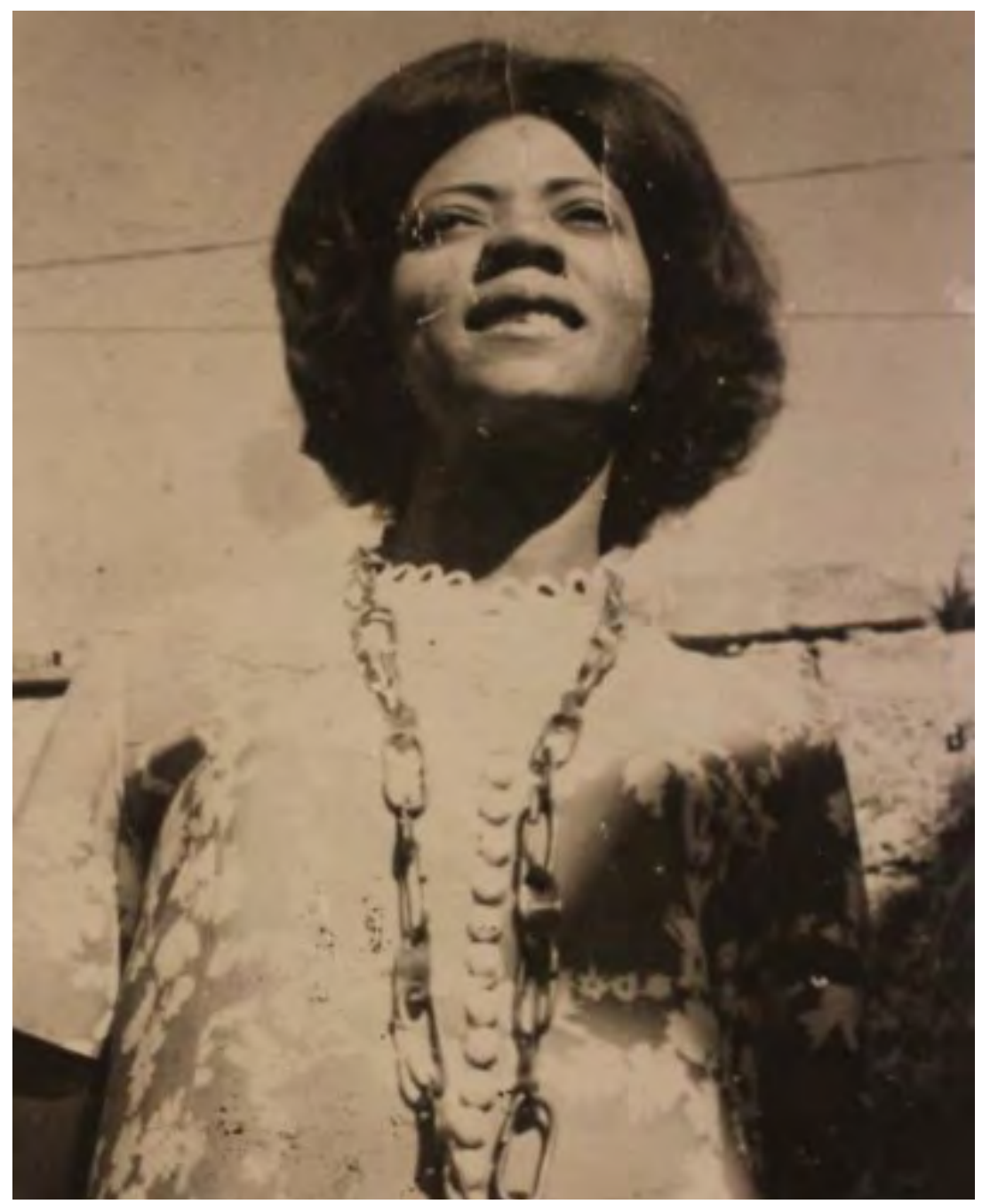

Fonte: MASP, Centro de Pesquisa Coleções. Maria Auxiliadora. Sem data. 1 fotografia. Fundo Maria Auxiliadora. Presente da Família Silva. 
Maria Auxiliadora: vida cotidiana, pintura e resistência é a segunda exposição solo da artista realizada no Masp; a primeira aconteceu em 1981 e foi organizada por Pietro Maria Bardi, fundador-diretor do museu e doador do primeiro trabalho de Auxiliadora para a coleção do museu (figura 4) Capoeira (1970)

\section{Figura 4: Capoeira}

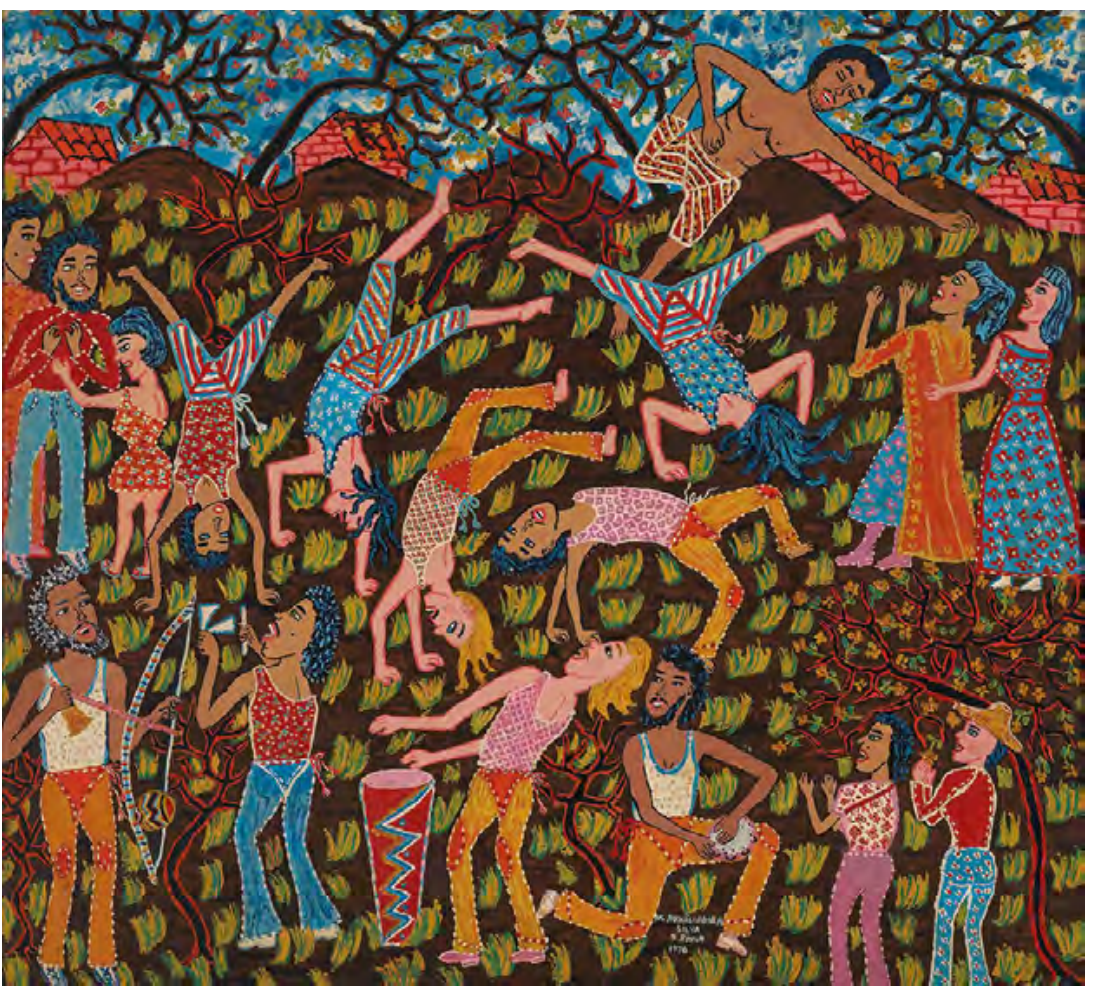

Fonte: SILVA, M. A. Capoeira. 1970. Técnica mista sobre tela, 69,5 x 75 × 1,5 cm. Doação Pietro Maria Bardi, 1981.

A segunda mostra sobre a vida e obra de Maria Auxiliadora foi a que deu início ao ciclo das histórias afro-atlânticas ${ }^{3}$, tema central da linha curatorial do Masp em 2018, que trabalhou a ideia dos "fluxos e refluxos" 4 entre a África - ou melhor, Áfricas -, Américas e o Caribe, através das diversas formas de arte.

A exposição de Maria Auxiliadora contou com 82 obras, divididas e narradas em sete núcleos diferentes: "Autorretratos", "Casais", "Interiores", "Manifestações populares", "Candomblé, umbanda e orixás", "Rural" e "Urbano" - temas caros e recorrentes das culturas afro-brasileiras, como também da vida e do cotidiano da artista. 0 samba, a capoeira, as religiosidades afro-diaspóricas, o dia a dia de mulheres negras e as suas bordas e bordados, a vida e a morte, são os temas que nos guiaram o mergulho na 
vida e obra da artista. Especificamente para essa resenha, escolhemos dar luz a dois dos núcleos mencionados acima: "Autorretratos" e "Candomblé, umbanda e orixás".

No núcleo "Autorretratos", Maria Auxiliadora acaba por fazer de si e de sua vida os temas centrais de sua pintura, colocando-se como artista, como a noiva que talvez nunca viesse a se casar e também como enferma - fazendo uma clara referência ao estado de saúde que a levou à morte aos 39 anos, em decorrência de um câncer.

\section{Figura 5: Velório da noiva}

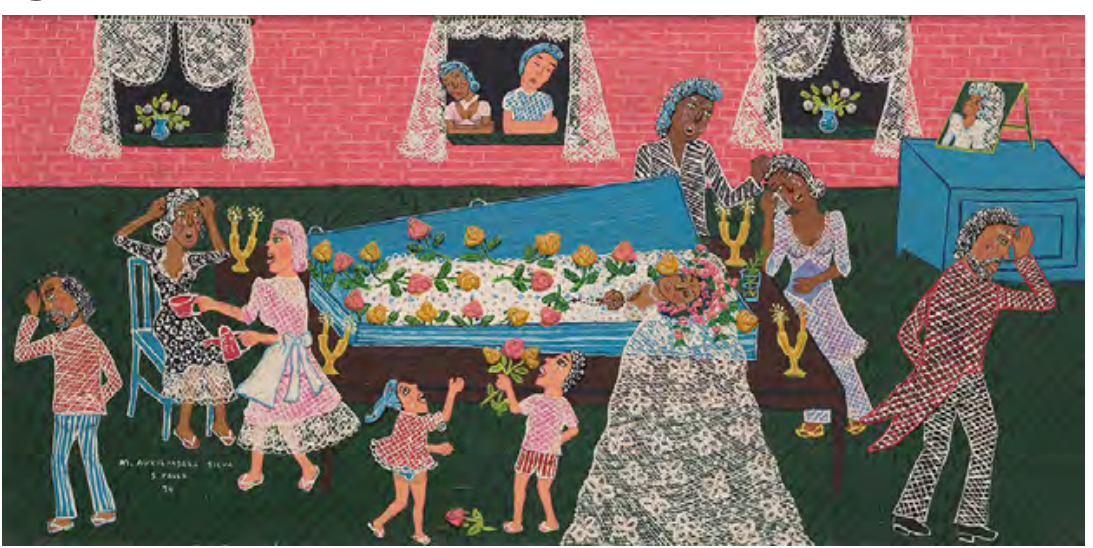

Fonte: SILVA, M. A. Velório da noiva. 1974. Técnica de óleo e massa de poliéster sobre tela, 50 x 100 cm. Doação da Fundação Edson Queiroz, 2015.

Na imagem acima, vemos o que gostamos de chamar de "os bordados" de Maria Auxiliadora Ao prestarmos atenção aos detalhes do quadro (figura 5), não podemos deixar de notar a presença do bordado e das rendas que compõem toda a representação dos tecidos, que vão das cortinas do velório às barras das saias das amigas e familiares que choram a partida da noiva que carrega um véu delicadamente florido por rendas brancas. A noiva, no caso, descobre-se mais tarde, que se trata da própria artista, que retrata o seu próprio funeral. Ao adentrarmos na biografia de Auxiliadora, é interessante saber que os bordados que vemos em muitas de suas obras nascem de uma referência de infância, quando sua mãe, que também tem intensa relação com a costura, ensina a Maria Auxiliadora o ofício de bordar (SANTORO, 2018). Notamos aqui a relação entre arte e pintura e métodos vestimentares que são transmitidos através das oralidades e conhecimentos familiares femininos. Outro fato precioso para entender a relação de Maria Auxiliadora com as vestimentas é que ela desenhava e costurava suas próprias roupas. Podemos ver muito desse interesse pela elaboração da indumentária quando observamos as obras da artista, nas quais notamos elaboradas construções das vestimentas dos personagens de suas pinturas. 
Figura 6: Autorretrato com anjos

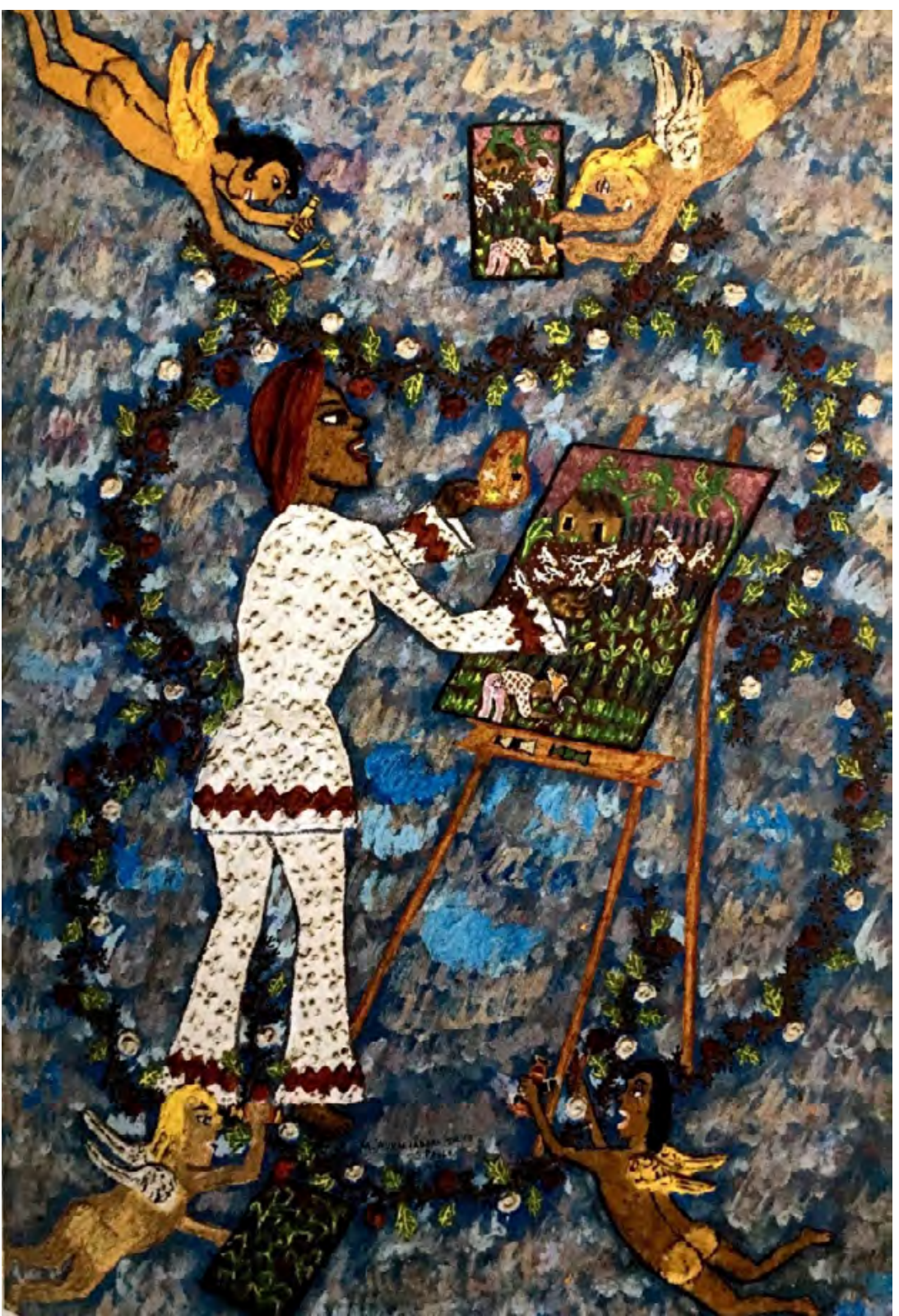

Fonte: SILVA, M. A. Autorretrato com anjos. 1972. Óleo sobre tela, $63.5 \times 45$ cm, técnica de óleo e massa de poliéster sobre tela, 50 × 100 cm. Coleção de Silvia e Mario Gorski, São Paulo, Brasil.

Na imagem acima (figura 6), vemos Maria Auxiliadora colocando-se na posição de personagem principal da pintura, no momento em que ela pinta alguma tela relacionada ao "Rural" - outro núcleo destacado na exposição -, vestida com conjunto branco com enfeites em vermelho, que combina com o seu torço, pintado também em cor rubra, amarrado à cabeça. 0 torço é muito recorrente na composição dos trajes da artista em sua vida cotidiana, aludindo claramente às estéticas vestimentares de mulheres ne- 
gras brasileiras e africanas. Na imagem ainda podemos perceber o caráter melancólico da pintura, ao notarmos que a artista se retrata rodeada por anjos negros e brancos que a "guardam", talvez em uma prévia de como seria a sua vida após a morte.

Como tema central do trabalho de Maria Auxiliadora, temos o núcleo "Candomblé, umbanda e orixás", que faz menção à parte da resistência negra brasileira que se estruturou por meio dos cultos religiosos de matriz africana.

\section{Figura 7: Candomblé}

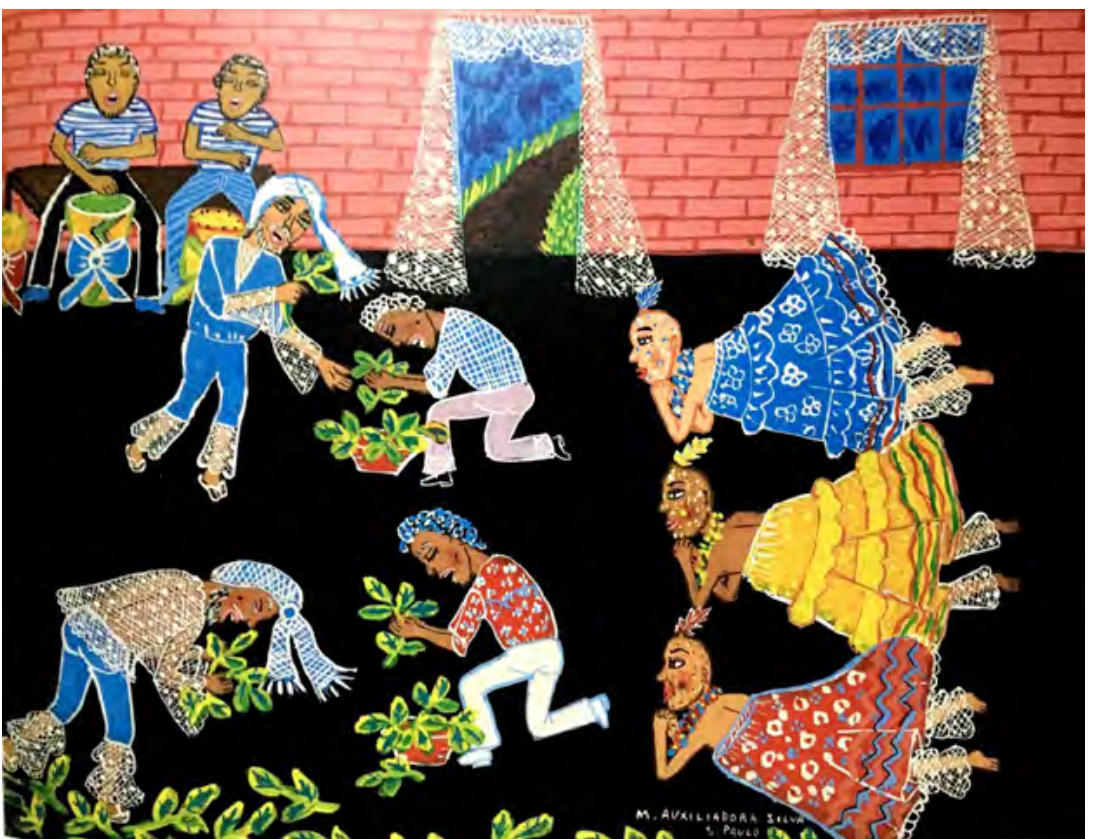

Fonte: SILVA, M. A. [Sem título] Candomblé. 1973. Óleo sobre tela, 25 × 33 cm. Coleção de Irapoan Cavalcanti, Rio de Janeiro, Brasil.

$\mathrm{Na}$ imagem destaca acima (figura 7), notamos uma referência ao que seria uma cerimônia de candomblé, em que podemos perceber, na parte direita da tela, três filhos de santo, adornados com pinturas rituais feitas em momentos de iniciação ou de renovação dos votos religiosos. Estão vestidos com as roupas e cores rituais de seus orixás, com uma indumentária composta por saias rodadas que têm a função de cobrir todo o corpo, adornadas com barras rendadas brancas, feitas com a mesma técnica de transpor tridimensionalidade à costura, criando o que podemos chamar de uma "costura-pintura". À esquerda vemos devotos envolvidos com os cuidados das folhas sagradas, usadas nos ritos afro-brasileiros, também vestidos de acordo com as regras de indumentária litúrgica dos candomblés: cabeças cobertas e adornadas com torços, batas e camisas também rendadas. Ao fundo vemos dois do que seriam os chamados ogãs 5 tocando os atabaques para que os deuses possam dançar. 
Figura 8: lemanjá segurando os seios

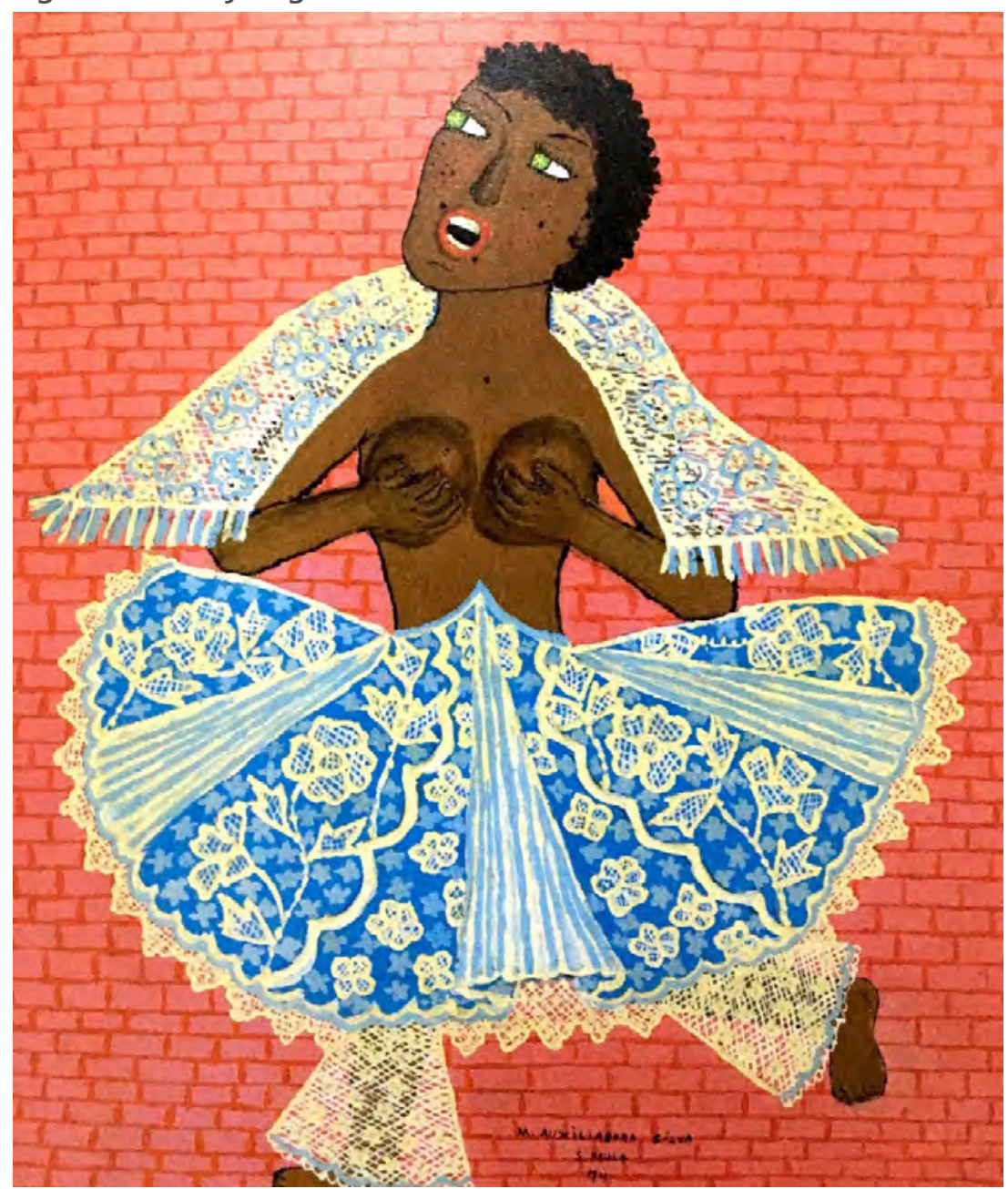

Fonte: SILVA, M. A. lemanjá segurando os seios. 1974. Óleo sobre tela, 57 x 47 cm. Coleção de Irapoan Cavalcanti, Rio de Janeiro, Brasil.

$\mathrm{Na}$ última imagem que selecionamos para contar as narrativas de Maria Auxiliadora através do núcleo expositivo "Candomblé, umbanda e orixás", vemos a figura de lemanjá (figura 8), negra com os olhos verdes e cabelos crespos e curtos, segurando os seios que, vistos na tela ao vivo, são tridimensionais e feitos com a técnica de massa mista, muito usada na obra da artista e caracteristica da sua já mencionada tridimensionalidade. Nas memórias e histórias africanas e afro-brasileiras, lemanjá que é considerada a rainha dos mares, e é, ou deveria ser, representada como uma mulher negra de seios muito fartos, para dar conta - de acordo com a sua figura materna - de alimentar todos os seus filhos. lemanjá é a mãe cujos filhos são peixes.

Em muitos terreiros de candomblé, ela, assim como a representação de Auxiliadora, veste as cores branco e azul, sempre adornada com rendas e 
saias rodadas. Para a cabeça, usa-se o torço, já mencionado acima e que, na obra da artista, aparece apenas como duas faixas de tecido igualmente bordadas e rendadas, em um entrelace dos tecidos azul e branco. Nas pernas, vemos o mesmo bordado em forma de um calçolão, e os pés descalços a dançar no chão do terreiro que se confunde ao que aparenta ser uma parede de tijolinhos.

É interessante notar, principalmente ao olharmos o núcleo "Candomblé, umbanda e orixás", a riqueza de detalhes com que Maria pinta toda a narrativa religiosa, como também as vestimentas desses ritos - que são específicas e parte constitutiva da religião. Os bordados, que são também descritos no texto de Bittencourt (2018), em método de técnica mista ganham caráter tridimensional, trazendo volume, textura e movimento às telas. Este movimento também é visto nas cerimônias afro-religiosas que Auxiliadora comunica em suas representações.

Mineira e migrante para São Paulo ainda pequena com sua familia, Maria Auxiliadora recria uma nova maneira de pintar, diferente dos já mencionados padrões e preceitos da chamada "academia de Belas Artes", muito questionada por ser embranquecida e eurocêntrica. A obra da artista, notada no contexto acima, ganha o sentido de resistência, na medida em que Maria Auxiliadora nos apresenta e representa o dia a dia de seus familiares e amigos das bordas da cidade de São Paulo, focando principalmente na zona norte da cidade, como os bairros da Casa Verde e Brasilândia - redutos negros, celeiros de religiosidades e festividades afro-brasileiras.

A frase "o pessoal é político", que inicia a exposição e essa resenha, é inspirada no argumento difundido pela feminista Carol Hanisch $(2009[1969])^{6}$, ainda nos de 1960, mas que se faz atual nos dias presentes, ao pensarmos a arte de uma mulher negra, vinda justamente dessas "bordas" e margens, ganhando espaço e visibilidade em um dos museus mais importantes da América Latina, por duas vezes. Maria Auxiliadora retira os negros da posição de objetos, e os retrata como semelhantes que são, sem o local de estranhamento de um observador branco. Aqui, quem observa e representa agora, é uma mulher negra, periférica, autodidata e contadora de sua própria história-arte. 


\section{NOTAS}

${ }^{1} 0$ título dessa resenha é uma tradução livre inspirada na frase "Auxiliadora paints as though she is embroidering" escrita dentro do texto "I paint creoles", de autoria de Renata Bittencourt, escrito no catálogo Maria Auxiliadora: daily life, painting and resistence (2018), do Masp.

${ }^{2}$ Maria Auxiliadora da Silva nasceu em Campo Belo (MG), em 15 de maio de 1935 e viveu até 1974, quando faleceu prematuramente aos 39 anos, em decorrência de um câncer.

${ }^{3}$ Divididas entre o Masp e o Instituto Tomie Ohtake, o ciclo das Histórias afro-atlânticas apresentou ao público uma seleção de 450 trabalhos de 214 artistas, do século 16 ao 21. Refletia, para além das exposições, através de cursos, palestras, shows e oficinas, a já mencionada relação entre Áfricas, Américas e Caribe e a presença do negro nas mais diversas manifestações artísticas.

${ }^{4}$ A expressão "fluxos e refluxos" cunhada no final dos anos 60, por Pierre Fatumbi Verger (2002) - fotógrafo, etnólogo e sacerdote iniciado para os cultos africanos e afro-brasileiros - e muito difundida durante 0 século XX, mostra as relações de conversa e semelhança entre as culturas e estéticas africanas e afrobrasileiras, através das memórias e heranças diaspóricas.

${ }^{5}$ Homens que não entram em transe, e são responsáveis, dentre muitas funções, por realizar o toque dos atabaques para estabelecer, através da música, a comunicação com os deuses negros.

${ }^{6}$ Nascida e criada em lowa, Estados Unidos, Carol Hanisch é feminista e atuante do Women's Liberation Movement (WLM). 0 movimento de libertação das mulheres foi um alinhamento político das mulheres e do intelectualismo feminista que surgiu no final da década de 1960. Ela é mais conhecida por popularizar a frase que "o pessoal é político" em um ensaio homônimo de 1969, no qual reflete sobre as diversas vivências do ser mulher e os problemas, que ultrapassam a esfera do eu e ganham o lugar do coletivo.

\section{REFERÊNCIAS}

BITTENCOURT, Renata. I paint creoles. In: Catalogue Maria Auxiliadora: daily life, painting and resistence. São Paulo: Museu de Arte de São Paulo (MASP), 2018. p. 32-40.

HANISCH, Carol. The personal is political. The Women's Liberation Movement classic with a new explanatory introduction. Carol Hanisch, 2009[1969]. Disponivel em: http://www.carolhanisch.org/ CHwritings/PIP.html. Acesso em: 24 fev. 2019.

MASP. Maria Auxiliadora: vida cotidiana, pintura e resistência. Masp, 2018. Disponivel em: https:// masp.org.br/exposicoes/maria-auxiliadora-da-silva-vida-cotidiana-pintura-e-resistencia. Acesso em: 3 fev. 2019.

SANTORO, Artur. Biographical Note. In: Catalogue Maria Auxiliadora: daily life, painting and resistence. São Paulo: Museu de Arte de São Paulo (MASP), 2018. p. 231-237.

VERGER, Fatumbi Pierre.Tráfico de escravos entre Benin e a Bahia. Bahia: Corrupio, 2002. 